\title{
Composição Química e Digestibilidade de Fenos Tratados com Amônia Anidra ou Uréia Ricardo Andrade Reis ${ }^{1 \star}$, Luis Roberto de Andrade Rodrigues ${ }^{1}$, João Ricardo Alves Pereira ${ }^{2 *}$, Ana Cláudia Ruggieri ${ }^{3}$
}

\begin{abstract}
RESUMO - O experimento foi conduzido para se avaliarem as alterações na composição química e na digestibilidade in vitro da matéria seca (DIVMS) dos fenos de Brachiaria decumbens Stapf, Brachiaria brizantha (Hochst ex. A. Rich) Stapf e jaraguá (Hyparrhenia rufa Ness Stapf), colhidos no estádio de maturação das sementes e tratados com amônia anidra (3,0\% MS) ou uréia (5,4\% MS). A análise dos dados demonstra que a amonização diminuiu os conteúdos de FDN e hemicelulose com a mesma eficiência. Os tratamentos químicos não alteraram os teores de FDA, celulose e lignina. Observou-se aumento nos teores de compostos nitrogenados, como $\mathrm{N}$ total e N insolúvel em detergente ácido (NIDA) em resposta à amonização. A relação NIDA/NT diminuiu com a amonização, aumentando a quantidade de $\mathrm{N}$ disponível para a digestão. A DIVMS aumentou em resposta às alterações observadas na composição química da fração fibrosa e incremento no conteúdo de $\mathrm{N}$ prontamente digestível dos fenos tratados.
\end{abstract}

Palavras-chave: amonização, composição química, digestibilidade, feno, gramíneas tropicais, uréia

\section{Chemical Composition and Digestibility of the Ammoniated Hays}

ABSTRACT - The experiment was conducted to evaluate the changes on the chemical composition and in vitro dry matter digestibility (IVDMD) of the Brachiaria decumbens Stapf, Brachiaria brizantha (Hochst ex. A. Rich) Stapf, jaragua (Hyparrhenia rufa Ness Stapf) hays, harvested following the seed ripening stage and treated with anhydrous ammonia (3.0\% DM) or urea (5.4\% DM). The data showed that anhydrous ammonia and urea decreased NDF and hemicellulose contents with the same efficiency. The treatments did not change ADF, cellulose, and lignin contents. It was observed an increase in the nitrogen as compounds, TN and ADIN due to the ammoniation. The ADIN/TN ratio was reduced due to the ammoniation. The IVDMD increased due to the changes observed in the chemical composition of the fiber, and the increase of the readily digestible nitrogen of the hays.

Key Words: ammoniation, chemical composition, digestibility, hays, tropical grasses, urea

\section{Introdução}

A produção de fenos de gramíneas forrageiras tropicais de alta qualidade, durante a estação chuvosa, é dificultada pela incidência de chuvas durante a secagem a campo.

Muitas vezes, para contornar os problemas climáticos, a fenação é realizada durante o outono, contudo, nesta época, o valor nutritivo das gramíneas de clima tropical é baixo. Tal fato ocorre em decorrência do alongamento dos caules, resultado do florescimento das plantas, com redução da relação folha/caule.

Assim, os fenos que sofreram processo prolongado de secagem, ou que receberam chuva durante o processamento a campo ou ainda aqueles oriundos de plantas colhidas no estádio de alongamento de caule apresentam baixo valor nutritivo (REIS et al., 1990a; 1991).

O valor nutritivo destes volumosos pode ser melho- rado com a aplicação de produtos químicos, sendo mais utilizados os hidróxidos de sódio, potássio, cálcio e amônio, a amônia anidra e a uréia como fonte de amônia (SUNDSTOL e COXWORTH, 1984; BERGER et al., 1994).

O tratamento com amônia anidra ou uréia promove alterações acentuadas na composição química do volumoso, principalmente nos componentes da fração fibrosa (REIS et al., 1990b; PEREIRA et al., 1993) e nos compostos nitrogenados (REIS et al., 1991; ROSA et al., 1998b).

Uma das principais alterações na composição química da fração fibrosa de volumosos tratados com amônia é a solubilização da hemicelulose, resultando em diminuição no conteúdo de FDN (TARKOW e FEIST, 1969; REIS et al., 1991; BROWN e ADJEI, 1995). Estudos que pesquisaram os efeitos da amonização sobre os conteúdos de FDA, celulose e lignina não são consistentes (SUNDSTOL, 1984;

\footnotetext{
1 Professor da FCAV/UNESP, 14870-000, Jaboticabal, SP. * Bolsista do CNPq. E.mail: rareis@fcav.unesp.br

2 Professor da Universidade Estadual de Ponta Grossa, 84010-330, Ponta Grossa, PR.

3 Pesquisadora do Instituto de Zootecnia, 14160-000, Sertãozinho, SP. E.mail: ruggieri@izsp.br
} 
REIS et al., 1990a). A análise desses dados evidencia elevação nos conteúdos de FDA e celulose nos volumosos tratados, o que pode ser explicado pela elevação proporcional nesses valores, devido à solubilização da hemicelulose, considerando que os resultados são expressos em termos percentuais. Por outro lado, alguns trabalhos têm mostrado decréscimo no conteúdo de lignina em resposta ao aumento no pH, ocorrendo, assim, a solubilização desses compostos (VAN SOEST, 1994).

Os resultados mais consistentes observados nas pesquisas sobre a amonização de volumosos é a elevação nos teores dos compostos nitrogenados, o que é atribuído ao conteúdo de $\mathrm{N}$ dos produtos usados, pois a $\mathrm{NH}_{3}$ possui 82,0\% de N, a água amônia, 25,0 a 30,0\% de $\mathrm{N}$ e a uréia, 46,5\% de N (SUDSTOL, 1984).

A determinação da forma como o nitrogênio foi incorporado a forragem é de suma importância na avaliação do valor nutritivo dos volumosos tratados com amônia (BUETTNER et al., 1982; MANSON et al., 1989a;MANSON et al., 1990), já que este pode ser retido sob diferentes formas. De acordo com SNIFFEN et al. (1992) e VAN SOEST e FOX (1992), as formas de $\mathrm{N}$ mais importantes em termos nutricionais são o $\mathrm{N}$ solúvel em água, o $\mathrm{N}$ amoniacal $\left(\mathrm{N}-\mathrm{NH}_{3}\right)$, o N retido na fração insolúvel em detergente neutro (NIDN) e o N retido na fração insolúvel em detergente ácido (NIDA).

Estudos conduzidos com gramíneas tropicais mostraram aumento nos teores de nitrogênio total (NT) e de nitrogênio insolúvel em detergente ácido (NIDA) em resposta à amonização (REIS et al.,1990b; 1991; 1995). Trabalhos de pesquisa conduzidos com volumosos de baixa qualidade submetidos à amonização evidenciam que a principal forma de retenção do $\mathrm{N}$ aplicado é a de N solúvel em água (SILANIKOVE et al., 1990; DIAS DA SILVA et al., 1990) e também o $\mathrm{N}$ amoniacal (MASON et al., 1989a; ROSA et al., 1998a).

O tratamento químico de volumosos de baixo valor nutritivo resulta em elevação na digestibilidade da celulose e da hemicelulose, em razão da expansão das moléculas de celulose, devido ao rompimento das pontes de hidrogênio e aumento da hidratação da fibra, permitindo o rápido acesso dos microrganismos, o que resulta, conseqüentemente, em maior digestibilidade (SCHIERE e NELL, 1993; BERGER et al., 1994).

Além dos aspectos mencionados, deve-se considerar a elevação no conteúdo de carboidratos prontamente fermentescíveis, bem como nos teores de NT, o que resulta em acréscimo na digestibilidade e no consumo dos volumosos tratados (PEREIRA et al., 1993; VAN SOEST, 1994). Os trabalhos com volumosos submetidos a amonização mostram que podem ocorrer aumentos de 8,0 a 12,0 unidades percentuais na digestibilidade da matéria seca (SUNDSTOL, 1984; SUNDSTOL e COXWORTH, 1984).

O experimento objetivou avaliar as alterações na composição química da fração fibrosa, os teores de compostos nitrogenados e a digestibilidade in vitro da matéria seca (DIVMS) dos fenos dos capins braquiária decumbens (Brachiaria decumbens Stapf, braquiária brizanta (Brachiaria brizantha (Hoschst ex. A. Rich) Stapf cv. Marandú) e jaraguá (Hyparrhenia rufa Ness Stapf), colhidos no estádio de maturação das sementes e tratados com amônia anidra ou uréia.

\section{Material e Métodos}

O experimento foi conduzido na FCAV/UNESP, Campus de Jaboticabal e os fenos foram produzidos na Estação Experimental de Sertãozinho, pertecente ao Instituto de Zootecnia do Estado de São Paulo, no período de abril a maio de 1996.

O corte das plantas foi realizado no período de 30 de abril a 04 de maio, quando as mesmas estavam com 100 dias de rebrota, correspondendo ao estádio de maturação das sementes, não sendo constatada a presença de perfilhos mortos.

O processo de fenação, ou seja, do corte ao enfardamento, foi realizado em três dias, obtendo-se fenos com $85 \%$ de matéria seca. Os fenos foram enfardados utilizando-se enfardadeira de fardo retangular, com peso médio de $12 \mathrm{~kg}$, sendo a seguir transportados para as dependências da FCAV/ UNESP, onde permaneceram armazenados em galpões arejados até o momento do tratamento químico.

Os fenos foram tratados com amônia anidra ou com uréia em 06 de junho de 1996 e, para a aplicação dos tratamentos, foram confeccionadas pilhas de fardos contendo aproximadamente $500 \mathrm{~kg}$ de MS cada uma.

Os fardos foram colocados sobre uma lona plástica arranjada em quatro camadas e cobertos com outra lona para armazenagem em condições herméticas durante o período de tratamento.

A amônia anidra foi injetada nos fardos na quantidade de 3,0\% do peso seco, contido em cada pilha de fardos, por meio de um tubo de PVC, de uma polegada, perfurado ao longo de sua extensão, colocado no centro de cada pilha de fardos e com uma das 
extremidades vedada e a outra contendo um dispositivo para se conectar à mangueira de aplicação de $\mathrm{NH}_{3}$, conforme recomendações de SUNDSTOL e COXWORTH (1984).

A aferição da quantidade de $\mathrm{NH}_{3}$ aplicada foi realizada mediante a pesagem contínua do cilindro de amônia, utilizando-se balança com capacidade de $500 \mathrm{~kg}$ e precisão de 100 gramas.

A uréia foi aplicada por aspersão, na proporção de $5,4 \%$ do peso seco das pilhas de fardos. A quantidade de nitrogênio aplicada foi equivalente àquela ao tratamento com amônia anidra. Aplicaram-se $24,3 \mathrm{~kg}$ de uréia (5,4\% do peso seco) diluída em 100 $\mathrm{L}$ de água, em cada pilha de fardos que continha 450 $\mathrm{kg}$ de MS. A quantidade de água foi calculada para elevar a umidade dos volumosos para $25 \%$. Este procedimento foi adotado para propiciar condições adequadas à atividade da urease presente nos volumosos, que, segundo SUNDSTOL e COXWORTH (1984), é máxima, quando o conteúdo de água da forragem varia de 25 a $30 \%$.

A solução de uréia foi distribuída com regador sobre as camadas, à medida que a pilha se formava sobre a lona de polietileno, observando-se as recomendações de JOY et al. (1992).

Foram confeccionadas pilhas de fardos não-tratados que permaneceram no campo sob as mesmas condições climáticas daquelas dos volumosos tratados com $\mathrm{NH}_{3}$ ou com uréia.

Após o período de tratamento de dois meses (06 de junho a 06 de agosto de 1996), em condições hermeticamente fechadas, as pilhas de fardos de fenos foram abertas para eliminação do excesso de $\mathrm{NH}_{3}$ que não reagiu com os volumosos e, após três dias, foram retiradas amostras para se efetuarem as determinações químicas.

As amostras recolhidas foram congeladas e, a seguir, moídas, evitando-se, dessa forma, as perdas de nitrogênio amoniacal durante a secagem em estufa.

As determinações químicas dos volumosos foram processadas no Laboratório de Forragicultura da FCAV/UNESP, avaliando-se os conteúdos de fibra em detergente neutro (FDN), fibra em detergente ácido (FDA), hemicelulose, celulose, lignina e proteína bruta (PB), segundo SILVA (1990). Também foram determinados os teores de nitrogênio insolúvel em detergente ácido (NIDA) no resíduo obtido após o tratamento das amostras com detergente ácido, observando-se os procedimentos preconizados por PEREIRA e ROSSI JR. (1994).

A digestibilidade in vitro da matéria seca
(DIVMS) foi determinada pela técnica de duas etapas, usando pepsina ácida, de acordo com TILLEY e TERRY (1963).

Os dados obtidos do arranjo fatorial composto por três tipos de fenos dos capins braquiária decumbens, braquiária brizanta e jaraguá, submetidos aos três tratamentos, controle, aplicação de amônia anidra ou uréia, foram analisados segundo o delineamento em blocos casualizados com três repetições, considerando-se como bloco as camadas de fardos dentro das pilhas, e as comparações entre médias foram realizadas pelo teste Tukey, a 5\% de probabilidade.

\section{Resultados e Discussão}

Os fenos tratados com amônia anidra ou com uréia apresentaram, após o período de tratamento, coloração escura, evidenciando as reações químicas entre a fração fibrosa e a amônia (SUNDSTOL e COXWORTH, 1984; SCHIERE e NELL., 1993).

Não se constataram deterioração e desenvolvimento de fungos durante o período de tratamento, apesar de o armazenamento dos fenos tratados com uréia ter sido feito com $25 \%$ de água, comprovando, assim, o efeito fungistático da amônia (GROTHEER et al., 1986; SILANIKOVE et al., 1990; ROSA et al., 1998b).

As análises dos dados apresentados nas Tabelas 1,2 e 3 evidenciam os altos teores dos constituintes da parede celular, baixos conteúdos de PB e valores de DIVMS dos fenos das gramíneas tropicais colhidas após o florescimento. Foram observados teores de FDN acima de 70,0\%, de FDA superiores a $45,0 \%$, de PB menores que 5,5\% e de DIVMS inferiores a 50,0\%, característicos de volumosos de baixo valor nutritivo (SUNDSTOL e COXWORTH, 1984; VAN SOEST, 1994).

A observação dos dados da Tabela 1 evidencia que a aplicação de amônia anidra ou de uréia acarretou diminuição $(\mathrm{P}<0,05)$ nos teores de FDN e de hemicelulose dos fenos avaliados.

Foram registrados decréscimos de 6,0 e 4,1 unidades percentuais nos teores de FDN e de 5,9 e de 3,5 nos de hemicelulose, em resposta à adição de amônia anidra ou de uréia nos fenos. Dessa forma, pode-se concluir que ambos os tratamentos tiveram a mesma eficiência em atuar sobre a fração fibrosa dos fenos. É importante salientar que, durante a aplicação da uréia, se procedeu à diluição em água, de tal forma a elevar o conteúdo de umidade dos fenos de 15,0 para 25,0\%, garantindo condições adequadas para a atuação da urease.

Em trabalhos de pesquisa conduzidos com fenos 
REIS et al.

Tabela 1 - Composição química dos fenos dos capins braquiária decumbens, braquiária brizantha e jaraguá não-tratados (NT), tratados com amônia anidra $(3,0 \% \mathrm{MS})$ ou uréia $(5,4 \% \mathrm{MS})$

Table 1 - Chemical composition of the braquiaria decumbens, braquiaria brizantha and jaragua hays non treated (NT), treated with anhydrous ammonia (3.0\% DM) or urea (5.4\% DM)

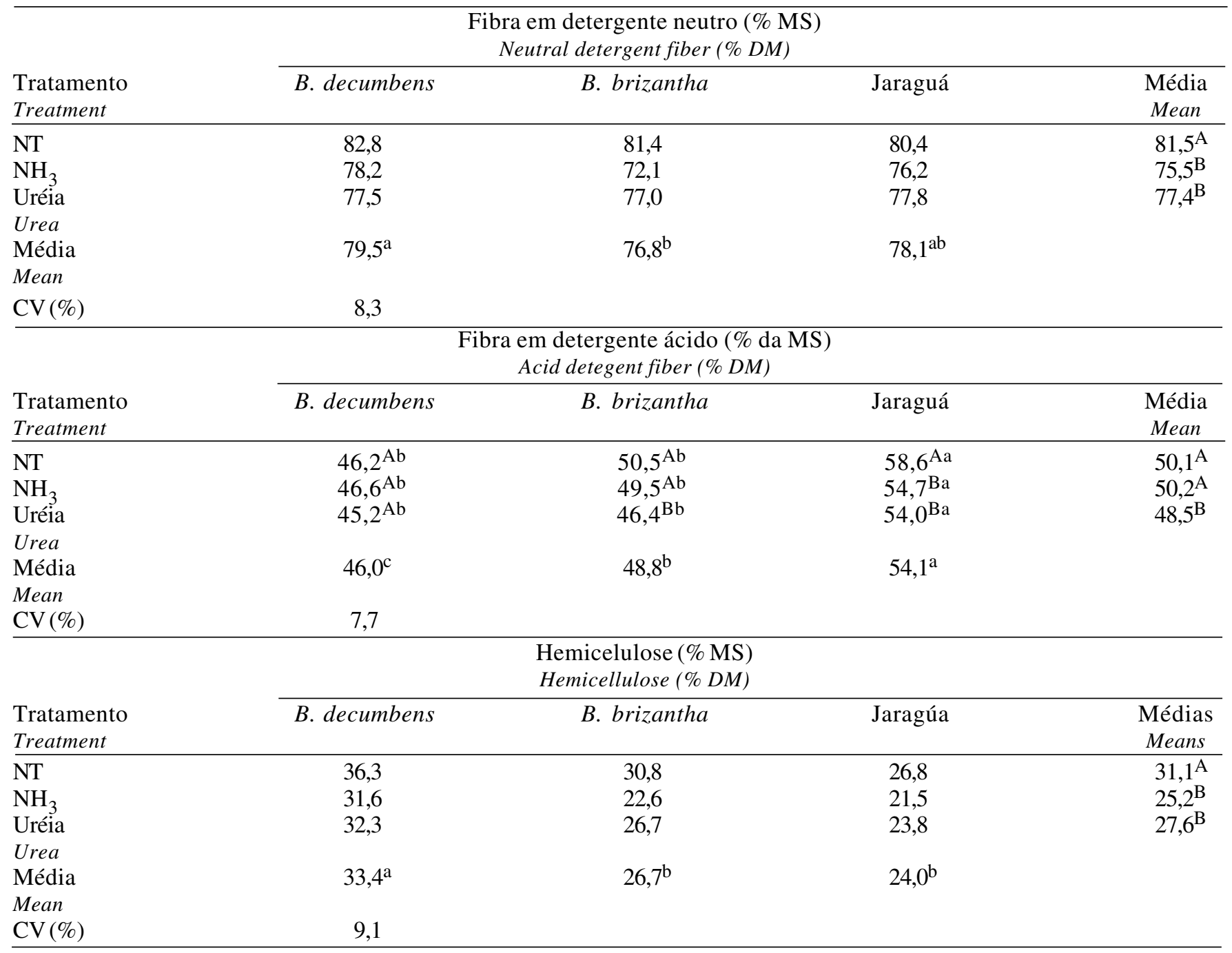

Médias seguidas de mesmas letras, maiúsculas nas colunas e minúsculas nas linhas, não diferem $(P>0,05)$ pelo teste Tukey. Means followed by the same letters, capital in the column and small in the row, are not different $(P>.05)$.

de capins tropicais tratados com $\mathrm{NH}_{3}$ (REIS et al., 1990a; PEREIRA et al., 1993; REIS et al., 1995) ou uréia (SILANIKOVE et al., 1990; BROWN e ADJEI, 1995; ROSA et al., 1998a), foram registradas diminuições nos teores de FDN e hemicelulose em resposta à amonização. Cumpre salientar que, nestas pesquisas, foram utilizadas quantidades de amônia anidra e uréia semelhantes às usadas no presente experimento.

Os teores de FDA dos fenos de B. brizantha e jaraguá (Tabela 1) foram afetados $(\mathrm{P}<0,05)$ somente pelo tratamento com uréia. Em relação aos teores de celulose (Tabela 2), observaram-se alterações $(\mathrm{P}<0,05)$ nos fenos do capim jaraguá tratado com $\mathrm{NH}_{3}$. Não foram observadas alterações $(\mathrm{P}>0,05)$ nos teores de lignina dos fenos amonizados (Tabela 2).
Com a amonização têm-se duas reações básicas, a amoniólise das ligações do tipo éster entre a lignina e a hemicelulose e a hidrólise alcalina, a qual promove o rompimento destas ligações, em função da alteração do pH (TARKOW e FEIST, 1969; BUETTNER et al., 1982).

Com a elevação acentuada do $\mathrm{pH}$, pode ocorrer a solubilização da lignina, sem, contudo, afetar o conteúdo de celulose (VAN SOEST, 1994). Assim, os dados de trabalhos de revisão apresentados por SUNDSTOL (1984) e BERGER et al. (1994) mostram que a principal alteração apresentada por volumosos de baixo valor nutritivo tratados com produtos hidrolíticos é a solubilização parcial das frações FDN e hemicelulose. 
Tabela 2 - Composição química dos fenos dos capins braquiária decumbens, braquiária brizantha e jaraguá não-tratados (NT), tratados com amônia anidra (3,0\% MS) ou uréia (5,4\% MS)

Table 2 - Chemical composition of the braquiaria decumbens, braquiaria brizantha and jaragua hays non treated (NT), treated with urea (5.4\% DM) or anhydrous ammonia (3.0\% DM)

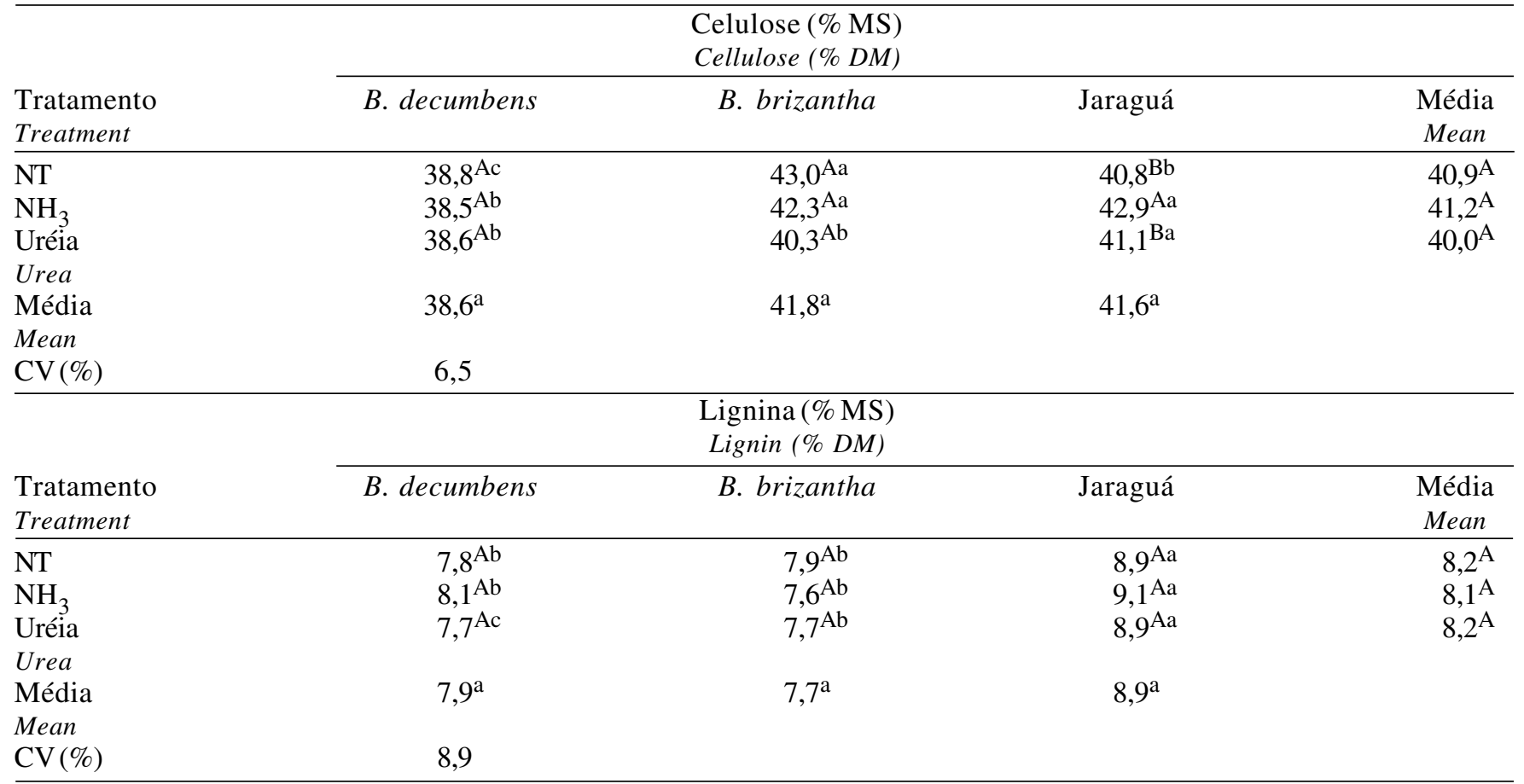

Médias seguidas de mesmas letras, maiúsculas nas colunas e minúsculas nas linhas, não diferem $(P>0,05)$ pelo teste Tukey. Means followed by the same letters, capital in the column and small in the row, are not different $(P>05)$.

Foram observados valores médios de nitrogênio insolúvel em detergente ácido (NIDA em \% MS) de 0,34; 0,30; e 0,44, respectivamente, para os fenos dos capins B. decumbens, B. brizantha e jaraguá. Quanto aos tratamentos foram registrados teores médios de NIDA (\% MS) de 0,$31 ; 0,42 ;$ e 0,36 , respectivamente para os fenos não tratados e tratados com amônia anidra $(3,0 \% \mathrm{MS})$ ou uréia $(5,4 \% \mathrm{MS})$. De maneira semelhante, REIS et al. (1990b; 1991) observaram aumento nos teores de NIDA, quando procederam a aplicação de amônia anidra em fenos de gramíneas de clima tropical. De acordo com MASON et al. (1989b), a retenção do $\mathrm{N}$ aplicado, na fração fibrosa dos volumosos tratados, ocorre principalmente no processo de termoamonização, no qual se utilizam altas temperaturas para o tratamento.

A relação NIDA/NT diminuiu $(\mathrm{P}<0,05)$ acentuadamente em resposta às aplicações de $\mathrm{NH}_{3}$ e uréia (Tabela 3).

Foram observados valores médios da relação NIDA/NT de 47,3; 20,6; e 15,9, respectivamente, para os fenos não tratados, tratados com amônia anidra ou com uréia. A observação destes dados evidencia que a adição de NNP da amônia anidra ou da uréia promoveu diluição do conteúdo de NIDA, aumentando a quantidade de $\mathrm{N}$ disponível para os microrganismos do rúmen, ou seja, NT menos a fração de NIDA (VAN SOEST e FOX, 1992; SNIFFEN et al., 1992).

Os teores de PB tiveram elevação média de 8,3 e 9,5 pontos percentuais com a aplicação de $\mathrm{NH}_{3}$ ou uréia, equivalente a retenção de 53,9 e 60,5\% do $\mathrm{N}$ aplicado.

É importante salientar que as amostras para determinação dos teores de PB foram coletadas três dias após a abertura das pilhas de fardos. Portanto, o $\mathrm{N}$ dosado foi aquele retido na fração fibrosa e na água contida nos volumosos, uma vez que o montante que não reagiu foi perdido por volatilização. Os fenos tratados com uréia apresentaram maior retenção do $\mathrm{N}$ aplicado (60,5\%), o que se deve ao maior conteúdo de água destes $(25,0 \%)$, comparado ao dos tratados com amônia anidra (12,0\% de umidade). A retenção do $\mathrm{N}$ aplicado pode ser aumentada, quando se trata de volumosos com maior conteúdo de água, devido à formação de hidróxido de amônia (BUETTNER et al., 1982; JOY et al., 1992).

Os resultados observados foram semelhantes aos encontrados por REIS et al. (1991), que registraram 
REIS et al.

Tabela 3 - Teores de compostos nitrogenados e valores de digestibilidade dos fenos dos capins braquiária decumbens, braquiária brizantha e jaraguá não-tratados (NT), tratados com amônia anidra $(3,0 \% \mathrm{MS})$ ou uréia $(5,4 \% \mathrm{MS})$

Table 3 - Nitrogen compounds contents and digestibility values of braquiaria decumbens, braquiaria brizantha and jaragua hays non treated (NT), treated with urea (5.4\% DM) or anhydrous ammonia (3.0\% DM)

\begin{tabular}{|c|c|c|c|c|}
\hline \multirow[b]{2}{*}{$\begin{array}{l}\text { Tratamento } \\
\text { Treatment }\end{array}$} & \multicolumn{3}{|c|}{$\begin{array}{l}\mathrm{N} \text { insolúvel em detergente ácido/ } \mathrm{N} \text { total } \\
\text { Acid detergent insoluble N/Total } N\end{array}$} & \multirow[b]{2}{*}{$\begin{array}{c}\text { Média } \\
\text { Mean }\end{array}$} \\
\hline & B. decumbens & B. brizantha & Jaraguá & \\
\hline NT & $47,7^{\mathrm{Aa}}$ & $50,0^{\mathrm{Aa}}$ & $44,1^{\mathrm{Aa}}$ & $47,3 \mathrm{~A}$ \\
\hline $\mathrm{NH}_{3}$ & $16,9^{\mathrm{Bb}}$ & $17,9^{\mathrm{Bb}}$ & $27,1^{\mathrm{Ba}}$ & $20,6 \mathrm{~B}$ \\
\hline Uréía & $16,1^{\mathrm{Ba}}$ & $15,4^{\mathrm{Ba}}$ & $16,3^{\mathrm{Ca}}$ & $15,9 \mathrm{C}$ \\
\hline \multicolumn{5}{|l|}{ Urea } \\
\hline Média & $26,9^{\mathrm{a}}$ & $27,9^{\mathrm{a}}$ & $29,2^{\mathrm{a}}$ & \\
\hline \multicolumn{5}{|l|}{ Mean } \\
\hline \multirow[t]{2}{*}{$\mathrm{CV}(\%)$} & 7,5 & & & \\
\hline & \multicolumn{3}{|c|}{$\begin{array}{c}\text { Proteína bruta }(\% \mathrm{MS}) \\
\text { Crude protein }(\% \mathrm{DM})\end{array}$} & \\
\hline $\begin{array}{l}\text { Tratamento } \\
\text { Treatment }\end{array}$ & B. decumbens & B. brizantha & Jaraguá & $\begin{array}{l}\text { Média } \\
\text { Mean }\end{array}$ \\
\hline$\overline{\mathrm{NT}}$ & $4,4^{\mathrm{Ba}}$ & $2,6^{\mathrm{Cb}}$ & $5,5^{\mathrm{Ba}}$ & $4,4^{\mathrm{B}}$ \\
\hline $\mathrm{NH}_{3}$ & $12,2^{\mathrm{Ab}}$ & $12,2^{\mathrm{Bb}}$ & $13,6^{\mathrm{Aa}}$ & $12,7^{\mathrm{A}}$ \\
\hline Uréía & $12,9^{\mathrm{Ab}}$ & $14,4^{\mathrm{Aa}}$ & $14,1^{\mathrm{Aa}}$ & $13,9^{\mathrm{A}}$ \\
\hline \multicolumn{5}{|l|}{ Urea } \\
\hline Média & $9,8^{\mathrm{b}}$ & $9,7^{b}$ & $11,0^{\mathrm{a}}$ & \\
\hline \multicolumn{5}{|l|}{ Mean } \\
\hline \multirow[t]{2}{*}{$\mathrm{CV}(\%)$} & 6,6 & & & \\
\hline & \multicolumn{3}{|c|}{$\begin{array}{l}\text { Digestibilidade in vitro da MS (\%) } \\
\text { In vitro DM digetibility (\%) }\end{array}$} & \\
\hline $\begin{array}{l}\text { Tratamento } \\
\text { Treatment }\end{array}$ & B. decumbens & B. brizantha & Jaraguá & $\begin{array}{c}\text { Média } \\
\text { Mean }\end{array}$ \\
\hline$\overline{\mathrm{NT}}$ & $48,7^{\mathrm{Ca}}$ & $41,2^{\mathrm{Cb}}$ & $46,8^{\mathrm{Ba}}$ & $45,6^{\mathrm{B}}$ \\
\hline $\mathrm{NH}_{3}$ & $63,5^{\mathrm{Aa}}$ & $61,6^{\mathrm{Aab}}$ & $58,4^{\mathrm{Ab}}$ & $61,2^{\mathrm{A}}$ \\
\hline Uréía & $59,8^{\mathrm{Ba}}$ & $55,8^{\mathrm{Bb}}$ & $56,4^{\mathrm{Ab}}$ & $57,3^{\mathrm{A}}$ \\
\hline \multicolumn{5}{|l|}{ Urea } \\
\hline Média & $57,4^{\mathrm{a}}$ & $52,9^{\mathrm{b}}$ & $53,9^{\mathrm{b}}$ & \\
\hline \multicolumn{5}{|l|}{ Mean } \\
\hline $\mathrm{CV}(\%)$ & 6,8 & & & \\
\hline
\end{tabular}

Médias seguidas de mesmas letras, maiúsculas nas colunas e minúsculas nas linhas, não diferem $(P>0,05)$ pelo teste Tukey.

Means followed by the same letters, capital in the column and small in the row, are not different $(P>.05)$.

retenção de 69,3 e 41,4\% e de 70,0 e 46,5\%, quando aplicaram 2,0 ou $4,0 \%$ de $\mathrm{NH}_{3}$ nos fenos de capim braquiária decumbens e gordura, respectivamente. Da mesma forma, ROSA et al. (1998a) encontraram retenção de 50,8 e 53,6\%, quando aplicaram $\mathrm{NH}_{3}$ ou uréia no feno de braquiária decumbens.

Foram observados aumentos médios $(\mathrm{P}<0,05)$ na DIVMS dos fenos tratados (Tabela 3) de 15,6 e 11,7 pontos percentuais, respectivamente, com a aplicação de $\mathrm{NH}_{3}$ ou de uréia. Os maiores aumentos na DIVMS foram registrados nos fenos de braquiária brizantha tratado com amônia anidra (20,4 unidades percentuais). Deve-se considerar que estes fenos tiveram as maiores diminuições nos teores de FDN e hemicelulose (Tabela 1), quando tratados com amônia anidra.
É importante ressaltar que as respostas dos volumosos ao tratamento com produtos hidrolíticos depende de características inerentes à planta, como por exemplo o poder tampão, que determina a resistência dos volumosos às variações no $\mathrm{pH}$ (LAU e VAN SOEST, 1981; DIAS-DA-SILVA e GUEDES, 1990). Dessa forma, os efeitos da amonização devido à hidrólise alcalina são limitados pelo alto poder tampão das plantas, bem como pela quantidade de hidróxido de amônia formado durante o tratamento químico, sendo este fato diretamente influenciado pelo conteúdo de água dos volumosos e pela quantidade de produto aplicada (GROTHEER et al.,1986, SILANIKOVE et al., 1990).

As alterações na composição química da fra- 
672 Rev. bras. zootec.

ção fibrosa, com a solubilização de parte da hemicelulose acarretando aumento no conteúdo de carboidratos prontamente digestíveis e de $\mathrm{N}$ disponível para os microrganismos do rúmen, provavelmente resultaram nos incrementos observados na DIVMS dos fenos (SUNDSTOL e COXWORTH, 1984; BERGER et al., 1994).

É importante salientar que os dados de digestibilidade apresentados na Tabela 3 foram obtidos pela técnica descrita por TILLEY e TERRY (1963), na qual se considera como digerida toda a porção não recuperada após as duas fases da digestão, ou seja, a de fermentação com pepsina ácida.

A amonização pode promover a solubilização da lignina, contudo, a análise dos dados da Tabela 2 evidencia que não houve solubilização desta fração, diminuindo a possibilidade de se superestimarem os valores de digestibilidade in vitro pela técnica de TILLEY e TERRY(1963).

Os valores de NIDA observados nos fenos tratados sugerem a não ocorrência da reação de Maillard. De acordo com MASON et al. (1989b) e VAN SOEST e MASON (1991), estas reações se desenvolvem em volumosos amonizados sob alta temperatura $\left(90^{\circ} \mathrm{C}\right) \mathrm{e}$, neste experimento, utilizou-se a técnica de SUNDSTOL e COXWORTH (1984), sendo o tratamento efetuado à temperatura ambiente.

Assim, pode-se concluir que os dados referentes à DIVMS observados neste experimento, com a amonização de fenos de gramíneas tropicais, foram semelhantes aos obtidos por REIS et al. (1990a; 1990b; 1991), com o uso de $\mathrm{NH}_{3}$, e aos de ROSA et al. (1998a) e REIS et al.(1995), utilizando uréia como fonte de amônia na avaliação da digestibilidade in vitro e in vivo dos volumosos de baixa qualidade.

\section{Conclusões}

A amonização nas dosagens utilizadas aumentou a digestibilidade dos volumosos de baixa qualidade, em decorrência das alterações observadas nos constituintes da parede celular e do maior conteúdo de nitrogênio disponível para o processo de digestão.

A uréia como fonte de amônia teve a mesma eficiência em alterar a composição química de todos os fenos estudados. Em relação à digestibilidade, o uso da uréia apresentou a mesma eficiência comparado com o uso da amônia no tratamento do feno de jaraguá, enquanto nos de braquiária os resultados foram inferiores.

\section{Referências Bibliográficas}

BERGER, L.L., FAHEY JR., G.C., BOURQUIM, L.O et al. 1994. Modification of forage quality after harvest. In: FAHEY JR. G.C. et al. (Ed.). Forage quality, evaluation e utilization. Madison: American Society of Agronomy. p.922-966.

BROWN, W.F., ADJEI, M. Urea treatment to improve the nutritional value of tropical forages. In: INTERNATIONAL CONFERENCE ON LIVESTOCK IN THE TROPICS, Gainesville, 1995. Proceedings... Gainesville: University of Florida, 1995. p.71-77.

BUETTNER, M.R., LECHTENBERG, V.L., HENDRIX, K.S., et al. 1982. Composition and digestion of ammoniated tall fescue (Festuca arundinacea Schreb.) hay). J. Anim. Sci., 54(1):173-178.

DIAS-DA-SILVA, A.A., GUEDES, C.V.M. 1990.Variability in the nutritive value of straw cultivars of wheat, rye and triticale and response to urea treatment. Anim. Feed Sci. Technol., 29(1-2):79-89.

GROTHEER, M.D., CROSS, D.L., GRIMES, L.W.1986. The effect of ammonia level and time of exposure to ammonia on the nutritional and preservatory characteristics of dry and high-moisture coastal bermuda grass hay. Anim. Feed Sci. and Technol., 14(1-2):55-65.

JOY, M., ALIBÉS, X., MUÑOZ, F. 1992. Chemical treatment of lignocellulosic residues with urea. Anim. Feed Sci. Techol., 38(3-4):319-333.

LAU, M.M., VAN SOEST, P.J. 1981.Titratable groups and soluble phenolic compounds as indicators of the digestibility of chemically treated roughage. Anim. Feed Sci. Technol., 6(1-2):123-131.

MASON, V.C., DHANOA, M.S., HARTLEY, R.D., KEENE, A.S. 1989a. Relationships between chemical composition, digestibility in vitro and cell wall degradability of wheat straw treated with different amounts of ammonia and at elevated temperature. Anim. Feed Sci. Technol., 24(3-4):293-306.

MASON, V.C., KEENE, A.S., COOK, J.E. et al. 1989b. Oven and stack ammoniation of grass hays. 1. Changes in chemical composition in relation to digestibility in vitro and cell wall degradability. Anim. Feed Sci. Technol., 24(3-4):299-311.

MASON,V.C., COOK, J.E., DHANOA, M.S. et al. 1990. Chemical composition, digestibility in vitro and biodegradability of grass hay oven-treated with different amounts of ammonia. Anim. Feed Sci. Technol., 29(3-4):237-249.

PEREIRA, J.R.A., EZEQUIEL, J.M.B., REIS, R.A. et al. 1993. Efeitos da amonização sobre o valor nutritivo do feno de capim braquiária. Pesq. Agrop. Bras., 28(12):1451-1455.

PEREIRA, J.R.A., ROSSI JR., P. 1994. Manual de avaliação nutricional de alimentos. Piracicaba: FEALQ. 34p.

REIS, R.A., GARCIA, R., QUEIROZ, A.C. et al. 1991. Efeitos da amonização sobre a qualidade dos fenos de gramíneas tropicais. Pesq. Agropec. Bras., 26(8):1183-1191.

REIS, R.A., GARCIA, R., SILVA, D.J. et al. 1990b. Efeitos da aplicação de amônia anidra sobre a digestibilidade do feno do capim-braquiária (Brachiaria decumbens Stapf). R. Soc. Bras. Zootec., 19(3):201-208.

REIS, R.A., GARCIA,R., QUEIROZ, A.C. et al. 1990a. Efeitos da aplicação de amônia anidra sobre a composição química e digestibilidade in vitro dos fenos de três gramíneas forrageiras de clima tropical. R. Soc. Bras. Zootec., 19(3):219-224.

REIS, R.A., RODRIGUES, L.R.A., PEDROSO, P. 1995. Ava- 


\section{REIS et al.}

liação de fontes de amônia para o tratamento de volumosos. R. Soc. Bras. Zootec., 24(4):486-493.

ROSA, B., REIS, R.A., PANIZZI, R.C. et al. 1998b. Preservação do feno de Brachiaria decumbens Stapf cv. Basilisk submetido a tratamento com amônia anidra ou uréia. $R$. Soc. Bras. Zootec., 27(4):691-694.

ROSA, B., REIS, R.A., RESENDE, K.T. et al. 1998a. Valor nutritivo do feno de Brachiaria decumbens Stapf cv. Basilisk submetido a tratamento com amônia anidra ou uréia. R. Soc. Bras. Zootec., 27(4): 815-822.

SCHIERE, J.B., NELL, A.J. 1993. Feeding of urea treated straw in the tropics. I. A review of its technical principles and economics. Anim. Feed Sci. Technol., 43(1-2):135-147.

SILVA, D.J. 1990. Análise de alimentos (métodos químicos e biológicos), 2.ed., Viçosa: UFV. 165p.

SILANIKOVE, N, BROSHA, A., HOLZER, Z. et al. 1990. Urea treatment of green panic: Effect on in vivo digestibility and on digesta means retention time. Anim. Feed Sci. Technol., 31(1-2):117-124.

SNIFFEN, C.J., O'CONNOR, J.D., VAN SOEST, P.J. et al. 1992. A net carbohydrate and protein system for evaluating cattle diets: 11. Carbohydrate and protein availability. J. Anim. Sci., 70(10):3562-3577.

SUNDSTOL, F. 1984. Ammonia treatment of straw: methods for treatment and feeding experience in Norway. Anim. Feed Sci. Technol., 10(2):173-187.
SUNDSTOL, F., COXWORTH, E.M. 1984. Ammonia treatment. In: SUNDSTOL, F., OWEN, E. (Eds.) Straw and others fibrous by-products as feed. Elsevier Press. p.196-247.

TARKOW, H., FEIST, W.C. 1969. A mechanism for improving the digestibility of lignocelulosic materials with dilute alkali and liquid ammonia. Adv. Chem. Ser., 95(1):197-218.

TILLEY, J.A., TERRY, A.R. 1963. A two-stage technique for in vitro digestion of forages crops. J. Br. Grassl. Soc., 18(1):104-111.

VAN SOEST, P.J., MASON, V.C. 1991. The influence of the Maillard reaction upon the nutritive value of fibrous feeds. Anim. Feed Sci. Technol., 32(1-2):45-53.

VAN SOEST, P.J. 1994. Nutritional ecology of the ruminant, 2.ed., New York: Cornell University Press. 476p.

VAN SOEST, P.J., FOX, D.G. Discounts for net energy and protein-fifth revision. In: CORNELL NUTRITIONAL CONFERENCE, 1992. Proceedings... Ithaca: University of Cornell, 1992. p.40-68.

Recebido em: 17/04/00

Aceito em: $12 / 12 / 00$ 